\title{
Brian Boyd
}

\section{SERENDIPITY OF THE NEW}

Special collections make even the jet-lagged scholar and the long-familiar subject seem special again. The hush, the concentration of energy and information, the respect the librarians have for the material and for those who come to consult it can inspire the neophyte and reanimate the aging expert.

Distinguished bibliographer G. Thomas Tanselle described the goal of bibliographical description in terms of attaining such precision as to provide a substitute for the original. But Karl Popper, the great philosopher of science, pointed out that precision in itself is a false goal in research because it makes sense only in regard to a particular problem. No one can tell what new problems another inquirer may raise or what new tools will make possible new standards of precision in this direction or that. For this very reason, even the fullest published descriptions or the most exact facsimiles are no substitute for the information an original may conceal until a new inquirer arrives with a fertile new question.

Special collections are special, then, because their individual items are special; but they also are special because they are collections. A scholar may assemble a personal working library of available publications and photocopies of the less easily accessible. But it takes the original and the rare to infuse an individual or an institution with the obsessive zeal needed to build a great collection. After a collection becomes great and its rarities are made available to others, researchers who consult it find that instead of ideas dying, as they can elsewhere in the wait for requests to arrive, they 
come in cascades as new works, new formats, new documents, new details, and the serendipity of new collocations rush to their attention.

In explaining what is universal about the impulse we in the Western world demarcate and designate as art, anthropologist Ellen Dissanayake eliminates all else until one common strand remains: "making special." There is indeed something artistic about the "specialness" that special collections impart to their materials, whether or not these materials seemed special when they were first produced. And in special collections, the impulse central to art stands at the service of the human sciences.

Special collections offer the presents, and the presence, of the past. They preserve what may or may not have seemed special at the time it appeared and impart to it a new specialness. They hoard the old to generate the new-and nothing is newer than discovery. 